\title{
Navigating the Minefield: Managing Refusal of Medical Care in Older Adults with Chronic Symptoms of Mental Illness
}

\author{
Cathal O'Cionnaith (D) \\ Anne PF Wand (iD) ${ }^{1-3}$ \\ Carmelle Peisah ${ }^{3,4}$ \\ 'Older Persons Mental Health Service, \\ Jara Unit, Concord Centre for Mental \\ Health, Concord Repatriation General \\ Hospital, Concord, NSW, Australia; \\ ${ }^{2}$ Specialty of Psychiatry, Faculty of \\ Medicine and Health, University of \\ Sydney, Sydney, NSW, Australia; \\ ${ }^{3}$ Discipline of Psychiatry, Faculty of \\ Medicine, University of New South \\ Wales, Sydney, NSW, Australia; ${ }^{4}$ Capacity \\ Australia, Crows Nest, NSW, Australia
}

Correspondence: Anne PF Wand Older Persons Mental Health Service, Jara Unit, Concord Centre for Mental Health, Concord Repatriation General Hospital, 109 Hospital Road, Concord, NSW, 2139, Australia

Tel +61297678940

Fax +61297678944

Email a.wand@unsw.edu.au
Purpose: The purpose of this case series is to illustrate the complexity of considerations across health (physical and mental), ethical, human rights and practical domains when an older adult with chronic symptoms of mental illness refuses treatment for a serious medical comorbidity. A broad understanding of these considerations may assist health care professionals in navigating this challenging but common aspect of clinical practice.

Case Presentation: Three detailed case reports are described. Participants were older adults with an acute presentation of a chronic mental illness, admitted to a specialized older persons mental health inpatient unit (OPMHU) in an Australian metropolitan hospital. Significant comorbid medical issues were detected or arose during the admission and the patient refused the recommended medical intervention. Data extracted from patients' medical records were analyzed and synthesized into detailed case reports using descriptive techniques. Each patient was assessed as lacking capacity for healthcare and treatment consent and did not have relatives or friends to assist with supported decision-making. Multifaceted aspects of decision-making and management are highlighted.

Conclusion: There are multiple complex issues to consider when an older adult with chronic symptoms of mental illness refuses treatment for serious comorbid medical conditions. In addition to optimizing management of the underlying mental illness (which may be impairing capacity to make healthcare decisions), clinicians should adopt a role of advocacy for their patients in considering the potential impact of ageism and stigma on management plans and inequities in physical healthcare. Consultation with specialist medical teams should incorporate multifaceted considerations such as potentially inappropriate treatment and optimum setting of care. Equally important is reflective practice; considering whether treatment decisions may infringe upon human rights or cause trauma.

Keywords: treatment refusal, human rights, capacity, ageism, psychiatric

\section{Introduction}

The poor physical health and premature mortality of people with mental illness compared to people without mental illness are well established. ${ }^{1-4}$ Several factors contribute to this disparity in health. These include (i) lifestyle factors (eg smoking, inactivity) $)^{4-6}$ compounded by medication-related factors (eg metabolic syndrome and obesity); ${ }^{7}$ (ii) the impact of symptoms of mental illness (eg disorganization, paranoia, avolition) on help-seeking behaviour; ${ }^{8-11}$ (iii) systemic factors such as poor integration between mental and physical health services ${ }^{8,10}$ and (iv) social inequity (eg homelessness, poverty) leading to poorer access to care. ${ }^{10,12}$ The risks 
of morbidity and mortality are magnified in older adults with mental illness, especially those with chronic symptoms. This group are more likely to have multimorbidity ${ }^{13,14}$ and additional ageing-related barriers to accessing healthcare such as sensory and cognitive impairment, ${ }^{15}$ reduced mobility and access to transport, ${ }^{16,17}$ higher service needs mismatched with more limited financial resources ${ }^{17}$ and poorly coordinated physical healthcare services. ${ }^{14}$ These barriers to care are compounded by ageism in health. A recent comprehensive systematic review of ageism across seven million participants over five continents, revealed significantly worse health outcomes due to ageism in over $95 \%$ of the studies across 11 health domains, including the mental-illness domain. ${ }^{18}$ Older adults with mental illness often face the unique problem of "double stigma"; negative attitudes towards both old age and mental illness. ${ }^{19-22}$

Additional factors underpinning the poor physical health of people with mental illness who present for medical care are treatment refusal and lack of decision-making capacity. ${ }^{23}$ Treatment refusal can occur in the presence or absence of decision-making capacity. ${ }^{24}$ The core elements of capacity are the ability to understand the information relevant to the decision, the ability to use or weigh that information as part of the decision-making process, and to communicate the decision. ${ }^{25}$ Common law establishes that an adult is presumed to have the capacity to consent to or refuse medical treatment unless that presumption is rebutted. ${ }^{26}$ However, capacity may be affected by symptoms of mental and physical illness, emotional state and cognition, which may fluctuate over time and resolve with treatment and support. ${ }^{27,28}$ With psychosis, for example, there may be symptoms such as delusional beliefs leading to mistrust of clinicians or denial of illness. ${ }^{28}$ Chronicity of symptoms may pose additional barriers to restoring capacity.

Thus, some people with mental illness may refuse medical treatment at a time when they lack capacity to give informed (competent) consent or refusal..$^{23,28}$ Unless the clinician recommending medical treatment recognizes the patient's lack of capacity, their treatment refusal may be accepted at face value. This may fuel ageist behaviors and attitudes such as lack of therapeutic zeal, demonstrated in clinician responses to medical illness amongst older adults. ${ }^{29}$ Thus, a person lacking capacity may be deprived of important medical care for a variety of reasons, ${ }^{23,26}$ adversely affecting his/her health and, potentially, lifespan.
Although refusal of medical treatment in people with mental illness is not uncommon in clinical practice, there is relatively little guidance from the literature about holistic management of the issue. Rubin et al (2018) proposed a 7-question algorithm to provide clinicians with an ethical framework for managing treatment refusal in patients lacking capacity. ${ }^{30}$ Case reports of medical treatment-refusal have been described in the literature, highlighting issues which may arise including impaired decision-making capacity, stigma and competing ethical principles ${ }^{9,23,31-37}$ although older adults, particularly those with mental illness, are underrepresented. Similarly, none of the aforementioned studies consider the specific ethical and human rights challenges pertinent to older adults, nor do they consider the combined interplay of medical and mental illness, and practical issues facing clinicians in the setting of treatment-refusal.

The aim of this case series is to illustrate the complexity of considerations across health (physical and mental), ethical, human rights and practical domains when an older adult with chronic symptoms of mental illness refuses treatment for a serious medical comorbidity.

\section{Materials and Methods Study Setting}

Participants were admitted to an Older Persons Mental Health Unit (OPMHU) in a public Australian metropolitan hospital in 2020. The OPMHU is a 30-bed specialized inpatient unit designed to deliver acute mental health care to persons aged 65 years and older. Older adults with a range of mental health problems may be admitted including people with mood disorders, psychosis, severe behavioral and psychological symptoms of dementia, adjustment disorders, substance misuse, and personality vulnerabilities. The unit is staffed by specialist OPMHtrained medical, nursing and allied health care professionals and offers a range of biological, psychotherapeutic, social, rehabilitation and diversional therapies.

\section{Case Selection}

Participants were older adults admitted with an acute presentation of a chronic mental illness and significant comorbid medical issues which were detected or arose during the admission and for which the patient refused the recommended medical intervention. Three illustrative cases were chosen which highlight the complexity of considerations 
for management across health (physical and mental), ethical, human rights and practical domains.

\section{Data Collection}

Data extracted from patients' medical records were analyzed and synthesized into detailed case reports using descriptive techniques. REDCap (a secure, passwordprotected, web-based data management tool designed for research) was used to capture and store de-identified research data. ${ }^{38,39}$ De-identified research data were entered into REDCap from the patients' electronic medical records. A second researcher verified that the data transferred were accurate and complete.

\section{Results}

Names of patients have been modified and replaced with a pseudonym. Pseudonyms are followed by an asterisk (eg Rose*) the first time they appear in the text.

\section{Case I}

John* is a 70-year-old man with schizophrenia who lives in a residential aged care facility (RACF) [nursing home/ long-term care facility]. He was referred for an involuntary admission to the OPMHU by the consultation-liaison psychiatry (CLP) team for management of psychosis, after being admitted to a general hospital for hemoptysis. Medical imaging had demonstrated a spiculated lung lesion, highly suspicious for malignancy. Additional medical issues included bilateral lower limb oedema of uncertain cause, and an unexplained mobility decline. John had refused further investigations and management of these issues. The medical team had recommended discharge with a plan for outpatient investigations.

The CLP team concluded that John's psychotic symptoms impaired his decision-making capacity in relation to treatment and follow-up of his numerous medical issues and therefore recommended inpatient treatment of his psychosis. On the OPMHU he demonstrated grandiose and persecutory delusions, including beliefs that he could control weather events and that he was being targeted by free radicals and radio waves. These delusions had been present for many years despite treatment with depot antipsychotics. Cognitive testing with the Rowland Universal Dementia Assessment Scale (RUDAS) ${ }^{40}$ revealed mild impairment (23/30). He was commenced on fortnightly risperidone depot.

Despite treatment of his psychotic symptoms, John continued to lack capacity for treatment consent. He believed his hemoptysis was due to poisoning at his RACF, and that he could not have cancer as he was no longer symptomatic. He refused the recommended investigation (a positron emission tomography [PET] scan) due to fears of radiation poisoning. John also demonstrated instability of choice with respect to investigations and management.

In Australia, a range of laws exist to guide appointment of substitute decision-makers for adults unable to give consent. $^{25,41}$ As John was socially isolated with no informal substitute decision-maker, he was appointed a Public Guardian. A Public Guardian in New South Wales (NSW), the jurisdiction of this case, is a public official appointed by the Guardianship Division of the NSW Civil and Administrative Tribunal ${ }^{42}$ with powers for substitute consent for health care and treatment for people with decisionmaking disabilities including, as in John's case, authority to override the person's objections. ${ }^{25}$

Venous ultrasound of John's lower limbs revealed a unilateral deep vein thrombosis (DVT). Treatment was complicated by John's intermittent refusal of therapeutic enoxaparin injections, which resulted in temporarily switching treatment to oral rivaroxaban as this was more acceptable to John, where possible trying to respect his will and preferences and minimize the over-riding of such. No cause was found for John's mobility decline. He engaged intermittently with physiotherapy, although did not progress to his premorbid level of walking independently likely due to sarcopenia from prolonged inactivity.

In liaison with respiratory medicine and with consent from the Guardian, after considering the risks and benefits of investigation and the potential severity of John's underlying lung condition, a decision was made to proceed with an endobronchial ultrasound (EBUS) of the mediastinal lymph nodes and a biopsy of the lung lesion. Consent for pre-anesthetic sedation was also provided, given John's refusal. Notably, John later communicated that he had been metaphorically "raped" by the involuntary invasive medical procedure.

Biopsy results of John's lung lesion revealed aspergillosis rather than malignancy. He assented to a course of an oral antifungal. There were residual, but improved, symptoms of psychosis on risperidone. After 13 weeks John was discharged to his RACF with follow-up appointments for management of his aspergillosis and DVT.

\section{Case 2}

Chris* is an 84-year-old man with schizophrenia who lives alone and has no family or friends. He was admitted 
involuntarily to the OPMHU for an exacerbation of his chronic psychotic symptoms. Chris had persecutory delusions which incorporated his neighbors, the department of public housing, police and health services. Consequently, he had a life-long mistrust of health services and avoidance of care. Treatment with risperidone was commenced.

Multiple previously unknown comorbidities were found on routine screening at admission, including anemia with severe vitamin B12 and iron deficiencies. Cognitive testing revealed moderate impairment (RUDAS $=17 / 30)$, possibly secondary to nutritional deficiencies. It also transpired that a pituitary lesion, suspected to be a macroadenoma, was identified the year before, although Chris had not followed-up with investigations.

Chris refused recommended management of these issues. He was assessed as lacking decision-making capacity with regards to health care and treatment consent. He had persecutory delusions, accusing the treating team of dishonesty and feigning his pathology results in order to appear superior to other hospitals. He also demonstrated illogicality, concrete thinking, perseveration and poor recall for medical information.

Chris was appointed a Public Guardian for health care and treatment consent. The Guardian consented to Chris having an intravenous iron infusion and a course of vitamin B12 injections. Parenteral administration was recommended by the gastroenterology team due to the severity of his nutritional deficiencies. Midazolam sedation was administered prior to the iron infusion to facilitate safe administration given Chris' ongoing refusal of treatment. He was subsequently administered a course of seven vitamin B12 injections over two weeks. A colonoscopy to investigate his nutritional deficiencies was cancelled because of his refusal to take the bowel preparation. An endoscopy revealed atrophic gastritis.

Chris was not amenable to magnetic resonance imaging (MRI) of his brain or visual field testing to investigate the pituitary lesion. However, there was biochemical evidence of hypogonadism, with associated long-term risk of osteoporosis/fracture, in addition to pituitary hemorrhage. These risks were contrasted with the risks of testosterone replacement and invasive surgical intervention. Upon further discussion with endocrinology and the Guardian, and taking these risks into account, it was concluded not to proceed with further intervention.

Chris's distress and preoccupation with his persecutory delusions attenuated during the admission. He was frustrated by the length of his admission and declared the numerous imposed injections (iron, vitamin B12 and risperidone) unnecessary and unjust. Following a 9-week admission, Chris was discharged home with follow-up appointments for his atrophic gastritis and pituitary lesion.

\section{Case 3}

Rose* is a 70-year-old woman with schizophrenia living in a boarding house. She had no informal substitute decision maker. She was admitted involuntarily to the OPMHU for treatment of an acute exacerbation of her chronic psychotic symptoms. These symptoms included delusions of pregnancy, delusions about her identity (having multiple people living inside her) and grandiose delusions that she, along with her "squires", could cure diseases and fight wars. She was cognitively impaired, scoring 21/30 in the Montreal Cognitive Assessment (MOCA). ${ }^{43}$ Rose was trialed on two different antipsychotic depots (paliperidone and zuclopenthixol) over the course of the admission.

During her admission, Rose had a mechanical fall which resulted in a left neck of femur and left distal radius fractures. Her treatment refusal for surgery was based on a delusional interpretation of her injuries, namely that they were incurred after being pushed over when out working with squires and did not result in fractures. She also believed her medical records had been falsified. On this basis she was found to lack capacity for treatment consent.

She was transferred to the orthopedic ward for operative management of her fractured hip. Consent was given for the operation by the Medical Superintendent according to Australian Mental Health Laws. ${ }^{41}$ Her distal radius fracture was managed conservatively.

Rose was required to remain non weight-bearing (NWB) for a period of six weeks postoperatively. She required a 1-1 nurse to effectuate this as she continued to deny having fractured her hip. She was transferred back to the OPMHU for ongoing treatment of her psychosis and completion of her NWB period. Rose was reviewed by the orthogeriatric team but not transferred to the rehabilitation unit due to a lack of beds, her preference to stay in the OPMHU, and concerns about disruptive behaviors. Although she continued to deny she had had a fracture or an operation, she was cooperative with physiotherapy and occupational therapy provided on the OPMHU. A Public Guardian was appointed to evaluate further healthcare decisions.

Rose had a second fall, this time sustaining an open fracture of her left distal radius. This was repaired surgically, with consent from her Guardian. Due to her multiple 
low trauma fractures, the geriatrics and endocrine teams recommended treatment for osteoporosis. Rose's Public Guardian provided consent for a zoledronic acid infusion and for investigation and management of emergent rectal bleeding/iron-deficiency anemia. A colonoscopy revealed hemorrhoids and she was treated with an iron infusion.

The intensity of Rose's psychotic symptoms improved over the course of the admission on zuclopenthixol. Following a seven-month admission she was discharged home with follow-up appointments for her osteoporosis and hemorrhoids.

\section{Discussion}

These three cases of older adults with chronic symptoms of mental illness and medical comorbidity illustrate the significant complexity and breadth of decision-making and care provision. In each case the person had long-standing mistrust of health services, neglect of health and refusal of treatment. Each person was socially isolated without relatives/friends and lacked capacity for health care and treatment consent. These are not unusual impediments to treatment and care for those with chronic mental illness, mandating a nuanced approach that considers a range of ethical and human rights challenges, while practically facilitating optimal mental and physical health treatment.

\section{Medical Futility and Potentially Inappropriate Treatment}

Although frequently used by clinicians in their decisionmaking, ${ }^{44,45}$ including in reference to patients unable to make decisions, ${ }^{46}$ the concept of medical futility is controversial and there is no generally accepted definition. ${ }^{44,46}$ This is the crux of the problem with futility. Although one simplified definition is "a clinical action serving no useful purpose in attaining a specified goal for a given patient", 47 such definitions have been criticized, as determination of treatment futility is subjective and based on the values of the clinician; ${ }^{45,48}$ what is futile for one clinician may not be for another. ${ }^{49}$ This is particularly so in the context of ageism and discrimination in health for older adults with mental illness. Although the concept of potentially inappropriate treatment is often preferred, ${ }^{50}$ the issues at stake are similar, namely a balance between several issues, including benefit and harm, consistency with personal values or ethical principles, and availability of resources. ${ }^{44}$

These issues were key to decision-making in two of the cases. For example, Chris's suspected pituitary macroadenoma was not further investigated or managed given there was a low chance of achieving meaningful benefit, which would outweigh the burden of potentially invasive surgical treatment, including the risks of requiring lifelong post-operative prednisone or desmopressin in a patient never adherent to oral medication. This contrasts with the management of Chris's nutritional deficiencies. Although he was asymptomatic, the anemia could affect his mood, energy and cognition, and may have heralded an underlying gastrointestinal malignancy; all potentially treatable. Thus, consent was sought from the Guardian to investigate and manage nutritional deficiencies. The expertise of specialist teams was important in determining whether to seek consent for each recommended intervention.

Feasibility of procedure is also relevant here. Treatment refusal may render certain procedures impractical, even with coercive measures. For example, a planned percutaneous core biopsy of John's lung lesion was cancelled as it required intraprocedural cooperation. Chris refused to drink bowel preparation, so his colonoscopy was also cancelled. Similarly, while it was considered "futile" by some medical teams to investigate John's suspected lung malignancy given the unfeasibility of delivering chemotherapy or radiotherapy to someone refusing treatment, the uncertainty of the diagnosis mandated advocacy from the OPMHU team, to investigate and diagnose what transpired to be aspergillosis, a treatable condition. Otherwise, with a presumed malignancy, he may have been considered palliative, influencing future treatment decisions. This highlights the potential subjectivity of futility as a concept, ${ }^{45,49}$ the potential danger of assuming the futility of treatment in a "difficult" patient refusing treatment, and may also reflect stigma.

\section{Stigma and Ageism}

Stigma towards people with mental illness exists among clinicians across healthcare disciplines, ${ }^{9,51-54}$ resulting in poorer quality of physical health care. ${ }^{8,51-56}$ Stigma potentially influenced the initial decision not to investigate John's lung lesion. It is also possible that Rose was declined inpatient rehabilitation after her hip fracture surgery due to stigmatization by clinicians. Although lack of beds was cited, she was not placed on a waiting list. Concerns about her being disruptive on a rehabilitation ward and her preference for OPMHU (despite demonstrated lack of capacity regarding the fracture) were 
prioritized over provision of usual comprehensive rehabilitation care post-fracture.

Patient age may also influence the management of treatment-refusal. Ageism has been defined as the stereotyping of and discrimination against individuals or groups based on their age, and has been identified as a priority for improving healthcare. ${ }^{57}$ Ageism may be reflected in the clinical practice and decision-making of clinicians, ${ }^{17,58}$ affecting the quality of health and social care that older adults receive. ${ }^{17,57,59}$ Patient age may have affected decision-making in the presented cases. For example, it seems surprising that John was initially to be discharged to his RACF from the medical ward, given his multiple uninvestigated medical issues. Would this have occurred with a younger person? Perhaps the complex combination of his age, difficult attitude, stigma towards people with mental illness, refusal of treatment (despite demonstrated lack of capacity), and presumed futility of investigation or management, resulted in him being recommended an impractical and unrealistic pathway in the form of outpatient care. Clinicians may not have been conscious of these influences in their decision-making.

\section{Autonomy, Beneficence and Non-Maleficence}

In the presented cases the ethical principle of beneficence was prioritized over non-maleficence and patient autonomy. ${ }^{60}$ Each patient made choices about their healthcare, which were largely driven by psychotic symptoms, that would inevitably result in pain, suffering and premature mortality. The identified lack of capacity for treatment consent led clinicians to intervene in the patient's best interests according to appropriate legal frameworks. ${ }^{41}$ It is possible that other clinicians, recognizing the potential distress to the patient in compelling them to have the refused medical investigation or treatment, would have prioritized non-maleficence over beneficence. Which approach is right? It could be considered negligent or manifest therapeutic nihilism to accept at face value a decision made without capacity when there are serious health implications. Conversely, to knowingly cause distress through imposing an invasive intervention on a person refusing it, even though they lack capacity to consent or refuse it, is ethically questionable and directly contravenes trauma-informed care, a paradigm underpinning the development and delivery of mental health services internationally. ${ }^{61-64}$ John was clearly traumatized by having treatment against his will, metaphorically equating his lung biopsy to "rape". Chris too emphasized that the injections administered (including vitamin B12) were a violation of his rights. There is considerable literature supporting their perspectives, highlighting the trauma experienced by mental health consumers in receipt of healthcare services, ${ }^{63,65}$ with clear implications for future engagement. In the presented cases, attempts were made to minimize the degree of potential inflicted trauma when choosing interventions. For example, John's delusional beliefs about radiation poisoning influenced a decision to cancel a planned PET scan (which involved administration of a radioactive tracer) and instead proceed with an EBUS/ biopsy.

\section{Human Rights}

The Convention on the Rights of Persons with Disabilities (CPRD) was passed by the United Nations in $2006^{66}$ with the aim of providing a legally binding international framework for protecting the rights of people with disabilities (including people living with chronic mental illness). ${ }^{67}$ Key here is Article 25, the right to enjoyment of the highest attainable standard of health without discrimination on the basis of disability. The embodiment of this right was actualized by ensuring access to equitable diagnosis and treatment of John's lung lesion and other medical comorbidities described.

However, other rights are at stake in these cases. The ongoing violation of human rights in psychiatric settings $^{68,69}$ and of older adults ${ }^{70-72}$ is well documented. The coercive treatment practices illustrated can impact on human rights by violating autonomy. ${ }^{73,74}$ With regard to international mental health and guardianship legislation, Article 12 of the CRPD ("Equal Recognition before the Law") has been interpreted as needing a shift away from traditional paternalistic substitute-decision-making (with a focus on "best interests" and risk reduction), towards supported decision-making, favoring the rights, will and preferences of the individual with disability/mental illness in all circumstances. ${ }^{67,75}$ The absence of a relative/friend to support decision-making and help determine preexisting wishes/preferences in these cases was noted.

Furthermore, a supported decision-making approach (as opposed to the substitute-decision making approach adopted in these cases) may be at odds with other important human rights. ${ }^{76}$ For example, without the application of relevant guardianship and mental health laws ${ }^{41}$ in the presented cases, the patients would have likely suffered 
premature morbidity and mortality, contravening the aforementioned Article 25 and Article 10 (the right to life) of the CRPD.

\section{Decision-Making Capacity}

Each of the presented cases was assessed as lacking capacity for health care and treatment consent. Inability to understand information about the nature and effect of their medical condition and proposed management was the main factor impairing capacity. All three patients did not believe the information provided about their medical condition, secondary to various delusions. In addition, cognitive impairment including impaired reasoning, perseveration and poor recall affected Chris's ability to understand and retain information given. Although mild cognitive impairment was noted in the other cases, it did not affect decision-making; an important consideration in capacity assessments. ${ }^{25}$

The starting point is the Common Law principle of presumption of capacity for all adults, regardless of diagnosis. ${ }^{25}$ There should be valid reason to rebut such presumptions, such as relapse of mental illness, to warrant a capacity assessment, and the assessment should occur in the context of a specific decision needing to be made. ${ }^{25}$ It is for this reason that we cannot presume anything about the decisional capacity of any of such patients until assessment. Furthermore, restriction of autonomy should be as brief as possible and, where feasible, efforts should be made to assist a person to regain capacity. ${ }^{31,77}$ Notably in Australia, guardianship and administration orders are time-limited with compulsory review embedded within the legislation. ${ }^{25}$ This is particularly relevant for mental illnesses such as depression or bipolar disorder which may have a relapsing remitting course, where capacity may be regained on treatment of the mental illness. ${ }^{31,78}$ Capacity may also be regained with diminution of acuity of symptoms in chronic schizophrenia.

\section{Setting of Care}

Older adults admitted to acute psychiatry inpatient units are frequently found to have significant comorbid physical illnesses that complicate patient care ${ }^{79}$ Furthermore, some people with mental illness often access mental health services as their first and only contact with the health system. $^{8}$ Thus, psychiatric admissions may facilitate opportunistic medical contact in patients who have unaddressed physical illnesses or have avoided healthcare services. For Chris in particular, his OPMHU admission resulted in the opportunistic detection of multiple unrecognized medical co-morbidities, which otherwise would have likely remained undiagnosed.

In the presented cases, much of the OPMHU admission duration was focused on delivering medical rather than psychiatric care (eg awaiting guardianship approval and procedure dates, facilitating post-procedure recovery/rehabilitation). There are ethical implications of extending the stay of involuntary patients in a locked mental health unit in order to focus on their medical care.

People with comorbid mental and physical illnesses may also be admitted to general hospitals, potentially presenting practical difficulties, particularly if the patient is disruptive and refusing care. ${ }^{80}$ General healthcare staff may have limited skills to manage people with cognitive disorders ${ }^{81}$ or mental illness, ${ }^{82}$ which can impact provision of holistic care.

Although in these cases the OPMHU was perhaps a more practical setting for addressing physical health issues than the general hospital, it may not have been the best location for efficient specialist multidisciplinary medical care. The resulting longer length of stay likely compounded distress in patients already refusing treatment. Combined medical-psychiatry units are a potential solution, the goals of which include improving physical and psychiatric care, reducing stigma, and increasing the costeffectiveness of inpatient stays by decreasing length of stay and readmissions. ${ }^{83}$ They have been especially beneficial for older adults with complex behavioral, medical and psychiatric symptoms as can occur in delirium. ${ }^{84}$

\section{Clinical Implications: The Way Forward}

This case series highlights the complexity and breadth of issues to be considered when an older adult with chronic symptoms of mental illness refuses treatment for serious medical comorbidity. Although some of the discussed management considerations are echoed elsewhere in the literature, ${ }^{30}$ our study (to our knowledge) represents a first in focusing on holistic management of treatment-refusal in this particular population, with wider ethical, practical and human rights considerations.

The inherent variety of opinions and ethical perspectives in such complex cases may understandably result in clinician uncertainty and anxiety. Clinical ethics committees have emerged in general hospital settings as independent bodies who provide a formal mechanism for dealing with complex ethical issues. ${ }^{85}$ Their goals include protecting patient rights and providing clinicians with advice and expert opinion 
regarding issues such as provision of treatment against a patient's wishes. ${ }^{85}$ They are beneficial in terms of improving satisfaction and reducing moral distress among clinicians, and may lead to changes in management plans. ${ }^{86}$ Peer review groups in psychiatry are another helpful means of discussing the inherent uncertainty and complexities of these cases. ${ }^{87}$

Education and training of clinicians to better understand and manage the complexity of treatment refusal is needed. Research has highlighted poor awareness among clinicians of human rights frameworks, ${ }^{71,72}$ and inadequate knowledge of capacity assessment ${ }^{24}$ and relevant legislative frameworks to manage treatment refusal. ${ }^{24,88,89}$

\section{Study Limitations}

There are some potential limits to the generalizability of this study's findings. Small case series, while rich in data and able to capture a complex array of issues, are by definition not generalizable. ${ }^{90}$ Moreover, by focusing on a particular theme, case series are not inclusive. For example, in this series, all three cases had chronic symptoms of psychosis and some had co-morbid cognitive impairment, thus the study did not demonstrate the impact of other types of mental illness (such as depression and anxiety) on treatment refusal. Nonetheless, the broader considerations highlighted in this study are applicable to all older adults with chronic symptoms of mental illness.

None of the cases had a supportive care network, which does not reflect the diversity of older adults' social networks, and the presence of which may have facilitated a supported decision-making approach ${ }^{91-93}$ to management and assisted in establishing the person's preexisting wishes and preferences.

Finally, this study took place within the Australian healthcare system. While it is beyond the scope of this case series to consider the myriad guardianship, administration and conservatorship legislation across all jurisdictions, Australia is bound by both Common Law and international human rights frameworks such as the CRPD. Notwithstanding variable legislation and application of the CRPD across various jurisdictions, there are widely applicable considerations relevant to all persons with mental health conditions including ethical and human rights of autonomy, equitable access to quality health care and respect for will and preferences, and Common Law principles of presumption of capacity. $^{25,94}$

\section{Conclusion}

There are multiple complex issues to consider when an older adult with chronic symptoms of mental illness refuses treatment for serious comorbid medical conditions. In addition to optimizing management of the underlying mental illness (which may be impairing capacity to make healthcare decisions), clinicians should adopt a role of advocacy for their patients in considering the potential impact of ageism and stigma on management plans and inequities in physical healthcare. ${ }^{1,3}$ Consultation with specialist medical teams should incorporate multifaceted considerations such as potentially inappropriate treatment and optimum setting of care. Clinicians require training in assessing decision-making capacity and navigating complex legislative frameworks relevant to treatment refusal. Equally important is reflective practice; considering whether treatment decisions may infringe upon human rights or cause trauma. Management of treatment refusal in older adults requires embracing the complexity and weighing up the overlapping ethical, practical and human rights factors for each individual, and seeking peer review and clinical ethics expertise when needed.

\section{Ethics Approval and Informed Consent}

Ethical approval for the study was obtained from Sydney Local Health District's Human Research Ethics Committee (Reference number CH62/6/2020-125). This study was conducted in accordance with the Declaration of Helsinki. Written consent for inclusion in the project and for publication was obtained from each of the patient's legally appointed guardians, as none of the patients had capacity to provide informed consent. However, all patients assented to their inclusion in the study.

\section{Acknowledgments}

The project was carried out as a part of the Royal Australian and New Zealand College of Psychiatrists (RANZCP) Fellowship requirement.

\section{Funding}

There was no funding for this paper.

\section{Disclosure}

The authors report no conflicts of interest in this work. 


\section{References}

1. World Health Organization. Guidelines for the Management of Physical Health Conditions in Adults with Severe Mental Disorders. Geneva: WHO; 2018.

2. Commonwealth of Australia. The Fifth National Mental Health and Suicide Prevention Plan. Canberra: National Mental Health Strategy; 2017.

3. Walker ER, McGee RE, Druss BG. Mortality in mental disorders and global disease burden implications: a systematic review and meta-analysis. JAMA Psychiatry. 2015;72(4):334-341. doi:10.1001/ jamapsychiatry.2014.2502

4. Happell B, Platania-Phung C, Webster S, et al. Applying the World Health Organization Mental Health Action Plan to evaluate policy on addressing co-occurrence of physical and mental illnesses in Australia. Aust Health Rev. 2015;39(4):370-378. doi:10.1071/ AH14098

5. Cooper J, Mancuso SG, Borland R, Slade T, Galletly C, Castle D. Tobacco smoking among people living with a psychotic illness: the second Australian Survey of Psychosis. Aust $N Z J$ Psychiatry. 2012;46(9):851-863. doi:10.1177/0004867412449876

6. Vreeland B. Bridging the gap between mental and physical health: a multidisciplinary approach. J Clin Psychiatry. 2007;68(Suppl 4):26-33.

7. Vancampfort D, Stubbs B, Mitchell AJ, et al. Risk of metabolic syndrome and its components in people with schizophrenia and related psychotic disorders, bipolar disorder and major depressive disorder: a systematic review and meta-analysis. World Psychiatry. 2015;14(3):339-347. doi:10.1002/wps.20252

8. Happell B, Platania-Phung C, Watkins A, et al. Developing an evidence-based specialist nursing role to improve the physical health care of people with mental illness. Issues Ment Health Nurs. 2019;40 (10):832-838. doi:10.1080/01612840.2019.1584655

9. Lyckholm LJ, Aburizik AK. Ethical management of patients with cancer and mental illness. AMA J Ethics. 2017;19(5):444-453.

10. Weinstein LC, Stefancic A, Cunningham AT, Hurley KE, Cabassa LJ, Wender RC. Cancer screening, prevention, and treatment in people with mental illness. CA Cancer J Clin. 2016;66(2):134-151. doi:10.3322/caac. 21334

11. Young SJ, Praskova A, Hayward N, Patterson S. Attending to physical health in mental health services in Australia: a qualitative study of service users' experiences and expectations. Health Soc Care Commun. 2017;25(2):602-611. doi:10.1111/hsc.12349

12. Colton CW, Manderscheid RW. Congruencies in increased mortality rates, years of potential life lost, and causes of death among public mental health clients in eight states. Prev Chronic Dis. 2006;3(2):A42.

13. Barnett K, Mercer SW, Norbury M, Watt G, Wyke S, Guthrie B. Epidemiology of multimorbidity and implications for health care, research, and medical education: a cross-sectional study. Lancet. 2012;380(9836):37-43. doi:10.1016/S0140-6736(12)60240-2

14. Houben N, Janssen E, Hendriks MRC, van der Kellen D, van Alphen BPJ, van Meijel B. Physical health status of older adults with severe mental illness: the PHiSMI-E cohort study. Int $J$ Ment Health Nurs. 2019;28(2):457-467. doi:10.1111/inm.12547

15. Wildenbos GA, Peute L, Jaspers M. Aging barriers influencing mobile health usability for older adults: a literature based framework (MOLD-US). Int J Med Inform. 2018;114:66-75. doi:10.1016/j. ijmedinf.2018.03.012

16. Volkert J, Andreas S, Harter M, et al. Predisposing, enabling, and need factors of service utilization in the elderly with mental health problems. Int Psychogeriatr. 2018;30(7):1027-1037. doi:10.1017/ S1041610217002526

17. Wyman MF, Shiovitz-Ezra S, Bengel J. Ageism in the health care system: providers, patients and systems. In: Ayalon L, Tesch-Romer C, editors. Contemporary Perspectives on Ageism. Cham, Switzerland: Springer; 2018:193-212.
18. Chang ES, Kannoth S, Levy S, Wang SY, Lee JE, Levy BR. Global reach of ageism on older persons' health: a systematic review. PLoS One. 2020;15(1):e0220857. doi:10.1371/journal.pone.0220857

19. Bodner E, Palgi Y, Wyman MF. Ageism in mental health assessment and treatment of older adults. In: Ayalon L, Tesch-Romer C, editors. Contemporary Perspectives on Ageism. Cham, Switzerland: Springer; 2018:241-262.

20. Peisah C, Brodaty H, O'Neill N. The mental health and rights of mentally ill older people. In: Dudley M, Silove D, Gale F, editors. Mental Health and Human Rights: Vision, Praxis and Courage. Oxford University Press; 2012.

21. de Mendonca Lima CA, Levav I, Jacobsson L, Rutz W. Stigma and discrimination against older people with mental disorders in Europe. Int J Geriatr Psychiatry. 2003;18(8):679-682. doi:10.1002/gps.877

22. Graham N, Lindesay J, Katona C, et al. Reducing stigma and discrimination against older people with mental disorders: a technical consensus statement. Int J Geriatr Psychiatry. 2003;18(8):670-678. doi:10.1002/gps.876

23. Kontos N, Freudenreich O, Querques J. "Poor insight": a capacity perspective on treatment refusal in serious mental illness. Psychiatr Serv. 2016;67(11):1254-1256. doi:10.1176/appi.ps.201500542

24. Lamont S, Stewart C, Chiarella M. Capacity and consent: knowledge and practice of legal and healthcare standards. Nurs Ethics. 2019;26 (1):71-83. doi:10.1177/0969733016687162

25. O'Neill N, Peisah C. Capacity and the law. 3rd ed.: Australasian Legal Information Institute (AustLII) communities; 2019: Available from: http://austlii.community/wiki/Books/CapacityAndTheLaw/. Accessed February 18, 2021.

26. Eagle K, Ryan CJ. Potentially incapable patients objecting to treatment: doctors' powers and duties. Med J Aust. 2014;200(6):352-354. doi:10.5694/mja12.11814

27. Trachsel M, Hermann H, Biller-Andorno N. Cognitive fluctuations as a challenge for the assessment of decision-making capacity in patients with dementia. Am J Alzheimers Dis Other Demen. 2015;30(4):360-363. doi:10.1177/1533317514539377

28. Van Staden CW, Kruger C. Incapacity to give informed consent owing to mental disorder. $J$ Med Ethics. 2003;29(1):41-43. doi:10.1136/jme.29.1.41

29. Peake MD, Thompson S, Lowe D, Pearson MG. Ageism in the management of lung cancer. Age Ageing. 2003;32(2):171-177. doi:10.1093/ageing/32.2.171

30. Rubin J, Prager KM. Guide to considering nonpsychiatric medical intervention over objection for the patient without decisional capacity. Mayo Clin Proc. 2018;93(7):826-829. doi:10.1016/j. mayocp.2018.04.005

31. Baruth JM, Lapid MI. Influence of psychiatric symptoms on decisional capacity in treatment refusal. AMA J Ethics. 2017;19(5):416-425.

32. Bingham SL. Refusal of treatment and decision-making capacity. Nurs Ethics. 2012;19(1):167-172. doi:10.1177/0969733011431925

33. Braun TL, Patel V, Dao H, Rosen T. What are the ethical and legal considerations when your patient refuses the standard of care? Dermatol Online J. 2019;25(8). doi:10.5070/D3258045125

34. Dempsey TM, DeMartino ES. How should clinicians navigate decision making for unrepresented patients? AMA J Ethics. 2019;21(7): E559-565.

35. Schwartz CE, Steinmuller RI, Dubler N. The medical psychiatrist as physician for the chronically mentally ill. Gen Hosp Psychiatry. 1998;20(1):52-61. doi:10.1016/S0163-8343(97)00094-7

36. Snow HA, Fleming BR. Consent, capacity and the right to say no. Med J Aust. 2014;201(8):486-488. doi:10.5694/mja13.10901

37. Wear AN, Brahams D. To treat or not to treat: the legal, ethical and therapeutic implications of treatment refusal. J Med Ethics. 1991;17 (3):131-135. doi:10.1136/jme.17.3.131

38. Harris PA, Taylor R, Minor BL, et al. The REDCap consortium: building an international community of software platform partners. J Biomed Inform. 2019;95:103208. doi:10.1016/j.jbi.2019.103208 
39. Harris PA, Taylor R, Thielke R, Payne J, Gonzalez N, Conde JG. Research electronic data capture (REDCap)--a metadata-driven methodology and workflow process for providing translational research informatics support. $J$ Biomed Inform. 2009;42(2):377-381. doi:10.1016/j.jbi.2008.08.010

40. Storey JE, Rowland JT, Basic D, Conforti DA, Dickson HG. The Rowland Universal Dementia Assessment Scale (RUDAS): a multicultural cognitive assessment scale. Int Psychogeriatr. 2004;16(1):13-31. doi:10.1017/S1041610204000043

41. Cheng K, Wand A, Ryan C, Callaghan S. An algorithm for managing adults who refuse medical treatment in New South Wales. Australas Psychiatry. 2018;26(5):464-468. doi:10.1177/1039856218758565

42. NSW Civil \& Administrative Tribunal. Guardianship division [Internet]. NSW; 2021. Available from: https://www.ncat.nsw.gov. $\mathrm{au} /$ ncat/how-ncat-works/ncat-divisions-and-appeal-panel/guardian ship-division.html. Accessed June 28, 2021.

43. Nasreddine ZS, Phillips NA, Bedirian V, et al. The Montreal Cognitive Assessment, MoCA: a brief screening tool for mild cognitive impairment. $J$ Am Geriatr Soc. 2005;53(4):695-699. doi:10.1111/j.1532-5415.2005.53221.x

44. Muller R, Kaiser S. Perceptions of medical futility in clinical practice - A qualitative systematic review. J Crit Care. 2018;48:78-84. doi:10.1016/j.jcrc.2018.08.008

45. Wilkinson DJ, Savulescu J. Knowing when to stop: futility in the ICU. Curr Opin Anaesthesiol. 2011;24(2):160-165. doi:10.1097/ ACO.0b013e328343c5af

46. Aghabarary M, Dehghan Nayeri N. Medical futility and its challenges: a review study. J Med Ethics Hist Med. 2016;9:11.

47. Kasman DL. When is medical treatment futile? A guide for students, residents, and physicians. J Gen Intern Med. 2004;19(10):1053. doi:10.1111/j.1525-1497.2004.40134.x

48. Truog RD, Brett AS, Frader J. The problem with futility. $N$ Engl J Med. 1992;326(23):1560-1564. doi:10.1056/ NEJM199206043262310

49. Palda VA, Bowman KW, McLean RF, Chapman MG. "Futile" care: do we provide it? Why? A semistructured, Canada-wide survey of intensive care unit doctors and nurses. J Crit Care. 2005;20 (3):207-213. doi:10.1016/j.jcrc.2005.05.006

50. Kon AA, Davidson JE. Retiring the term futility in value-laden decisions regarding potentially inappropriate medical treatment. Crit Care Nurse. 2017;37(1):9-11. doi:10.4037/ccn2017234

51. Henderson C, Noblett J, Parke H, et al. Mental health-related stigma in health care and mental health-care settings. Lancet Psychiatry. 2014;1(6):467-482. doi:10.1016/S2215-0366(14)00023-6

52. Knaak S, Mantler E, Szeto A. Mental illness-related stigma in healthcare: barriers to access and care and evidence-based solutions. Healthc Manage Forum. 2017;30(2):111-116. doi:10.1177/ 0840470416679413

53. Thornicroft G, Rose D, Kassam A. Discrimination in health care against people with mental illness. Int Rev Psychiatry. 2007;19 (2):113-122. doi:10.1080/09540260701278937

54. Ostrow L, Manderscheid R, Mojtabai R. Stigma and difficulty accessing medical care in a sample of adults with serious mental illness. $J$ Health Care Poor Underserved. 2014;25(4):1956-1965. doi:10.1353/hpu.2014.0185

55. Abbey S, Charbonneau M, Tranulis C, et al. Stigma and discrimination. Can J Psychiatry. 2011;56(10):1-9.

56. Knaak S, Patten S, Ungar T. Mental illness stigma as a quality-ofcare problem. Lancet Psychiatry. 2015;2(10):863-864. doi:10.1016/ S2215-0366(15)00382-X

57. World Health Organization. World Report on Ageing and Health. Geneva: World Health Organization; 2015.

58. Robb C, Haley WE, Haley WE. Ageism in mental health and health care: a critical review. J Clin Geropsychol. 2002;8(1):1-12. doi:10.1023/A:1013013322947
59. Burnes D, Sheppard C, Henderson CR, et al. Interventions to reduce ageism against older adults: a systematic review and meta-analysis. Am J Public Health. 2019;109(8):e1-e9. doi:10.2105/ AJPH.2019.305123

60. Beauchamp TL, Childress JF. Principles of Biomedical Ethics. 8th ed. New York: Oxford University Press; 2019.

61. Mental Health Coordinating Council. Trauma-Informed Care and Practice: Towards a Cultural Shift in Policy Reform Across Mental Health and Human Services in Australia, a National Strategic Direction, Position Paper and Recommendations of the National Trauma-Informed Care and Practice Advisory Working Group. NSW: Mental Health Coordinating Council; 2013.

62. National Mental Health Commission. A Case for Change: Position Paper on Seclusion, Restraint and Restrictive Practices in Mental Health Services. NSW: National Mental Health Commission; 2015.

63. Muskett C. Trauma-informed care in inpatient mental health settings: a review of the literature. Int J Ment Health Nurs. 2014;23(1):51-59. doi:10.1111/inm. 12012

64. Sweeney A, Filson B, Kennedy A, Collinson L, Gillard S. A paradigm shift: relationships in trauma-informed mental health services. BJPsych Adv. 2018;24(5):319-333. doi:10.1192/bja.2018.29

65. Isobel S, Wilson A, Gill K, Howe D. 'What would a trauma-informed mental health service look like?' Perspectives of people who access services. Int J Ment Health Nurs. 2020.

66. United Nations. Convention on the rights of persons with disabilities; 2006. Available from: https://www.un.org/development/desa/disabil ities/convention-on-the-rights-of-persons-with-disabilities.html. Accessed February 10, 2021.

67. Callaghan S, Ryan CJ. Rising to the human rights challenge in compulsory treatment--new approaches to mental health law in Australia. Aust N Z J Psychiatry. 2012;46(7):611-620. doi:10.1177/ 0004867412438872

68. Pariseau-Legault P, Vallee-Ouimet S, Goulet MH, Jacob JD. Nurses' perspectives on human rights when coercion is used in psychiatry: a systematic review protocol of qualitative evidence. Syst Rev. 2019;8 (1):318. doi:10.1186/s13643-019-1224-0

69. World Health Organization. Mental health, human rights \& legislation; 2021. Available from: https:/www.who.int/mental_health/pol icy/legislation/en/. Accessed February 10, 2021.

70. Byrnes A. Human rights unbound: an unrepentant call for a more complete application of human rights in relation to older persons-and beyond. Australas J Ageing. 2020;39(2):91-98. doi:10.1111/ ajag. 12800

71. Peisah C, Byrnes A, Doron II, Dark M, Quinn G. Advocacy for the human rights of older people in the COVID pandemic and beyond: a call to mental health professionals. Int Psychogeriatr. 2020;32 (10):1199-1204. doi:10.1017/S1041610220001076

72. Peisah C, Jessop T. A human rights response to the Royal Commission. Austr J Dement Care. 2020;9(1):10-11.

73. Porsdam Mann S, Bradley VJ, Sahakian BJ. Human rights-based approaches to mental health: a review of programs. Health Hum Rights. 2016;18(1):263-276.

74. Gostin LO, Gable L. The human rights of persons with mental disabilities: a global perspective on the application of human rights principles to mental health. MD Law Rev. 2004;63(1):20-121.

75. Callaghan S, Ryan CJ. An evolving revolution: evaluating Australia's compliance with the Convention on the Rights of Persons with Disabilities in mental health law. Univ $N S$ W Law J. 2016;39 (2):596-624.

76. Freeman MC, Kolappa K, de Almeida JM, et al. Reversing hard won victories in the name of human rights: a critique of the General Comment on Article 12 of the UN Convention on the Rights of Persons with Disabilities. Lancet Psychiatry. 2015;2(9):844-850. doi:10.1016/S2215-0366(15)00218-7 
77. Barstow C, Shahan B, Roberts M. Evaluating medical decision-making capacity in practice. Am Fam Physician. 2018;98 (1):40-46.

78. Gergel T, Owen GS. Fluctuating capacity and advance decision-making in Bipolar Affective Disorder - self-binding directives and self-determination. Int J Law Psychiatry. 2015;40:92-101. doi:10.1016/j.ijlp.2015.04.004

79. Draper B, Luscombe G. The effects of physical health upon the outcome of admission to an acute psychogeriatrics ward. Australas J Ageing. 1999;18(3):134-139. doi:10.1111/j.1741-6612.1999. tb00114.x

80. Stern TA, Freudenreich O, Smith FA, Fricchione GL, Rosenbaum JF. Massachusetts General Hospital Handbook of General Hospital Psychiatry. 7th revised ed. Philadelphia: Elsevier; 2017.

81. Clissett P, Porock D, Harwood RH, Gladman JR. The responses of healthcare professionals to the admission of people with cognitive impairment to acute hospital settings: an observational and interview study. $J$ Clin Nurs. 2014;23(13-14):1820-1829. doi:10.1111/ jocn. 12342

82. Sharrock J, Happell B. Competence in providing mental health care: a grounded theory analysis of nurses' experiences. Aust J Adv Nurs. 2006;24(2):9-15

83. Caarls PJ, van Schijndel MA, Berk GVD, et al. Factors influencing the admission decision for Medical Psychiatry Units: a concept mapping approach. PLoS One. 2019;14(9):e0221807. doi:10.1371/journal.pone. 0221807

84. Wand AP, George J. Observations of a traveling fellow: consultation-liaison psychiatry versus joint units for delirium management. Int Psychogeriatr. 2013;25(7):1204-1206. doi:10.1017/S1041610213000124

85. Rasoal D, Skovdahl K, Gifford M, Kihlgren A. Clinical ethics support for healthcare personnel: an integrative literature review. $H E C$ Forum. 2017;29(4):313-346. doi:10.1007/s10730-017-9325-4
86. Crico C, Sanchini V, Casali PG, Pravettoni G. Evaluating the effectiveness of clinical ethics committees: a systematic review. Med Health Care Philos. 2020;24:135-151. doi:10.1007/s11019-02009986-9

87. Lancaster J, Prager S, Nash L, Karageorge A. Psychiatry peer review groups in Australia: a mixed-methods exploration of structure and function. BMJ Open. 2020;10(11):e040039. doi:10.1136/bmjopen2020-040039

88. Panesar N, Valachova I, Schmidtman R, Chan DKY. Staff awareness of the application of Mental Health and Guardianship Legislation in the care of hospitalised older persons. Australas Psychiatry. 2018;26 (5):469-473. doi:10.1177/1039856218758545

89. Wand A, Maheshwari R, Holton M. Mindful of the gaps: enhancing psychiatry training through a trainee workshop. Australas Psychiatry. 2012;20(3):231-236. doi:10.1177/1039856212436748

90. Cassell C, Symon G. Essential Guide to Qualitative Methods in Organizational Research. London: Sage Publications; 2004.

91. Jeste DV, Eglit GML, Palmer BW, Martinis JG, Blanck P, Saks ER. Supported decision making in serious mental illness. Psychiatry. 2018;81(1):28-40. doi:10.1080/00332747.2017.1324697

92. Kokanovic R, Brophy L, McSherry B, Flore J, Moeller-Saxone K, Herrman H. Supported decision-making from the perspectives of mental health service users, family members supporting them and mental health practitioners. Aust $N$ Z J Psychiatry. 2018;52 (9):826-833. doi:10.1177/0004867418784177

93. Peisah C, Sorinmade OA, Mitchell L, Hertogh CM. Decisional capacity: toward an inclusionary approach. Int Psychogeriatr. 2013;25 (10):1571-1579. doi:10.1017/S1041610213001014

94. Peisah C, de Mendonca Lima C, Verbeek H, Rabheru K. IPA and WPA-SOAP joint statement on the rights of older persons with mental health conditions and psychosocial disabilities. Int Psychogeriatr. 2021;1-5.
Clinical Interventions in Aging

\section{Publish your work in this journal}

Clinical Interventions in Aging is an international, peer-reviewed journal focusing on evidence-based reports on the value or lack thereof of treatments intended to prevent or delay the onset of maladaptive correlates of aging in human beings. This journal is indexed on PubMed Central, MedLine, CAS, Scopus and the Elsevier
Bibliographic databases. The manuscript management system is completely online and includes a very quick and fair peer-review system, which is all easy to use. Visit http://www.dovepress.com/ testimonials.php to read real quotes from published authors. 